Table. Variation of clinical and serologic disease activity variables in patients with active lupus treated with belimumab

\begin{tabular}{|c|c|c|c|c|c|c|c|c|c|c|}
\hline & pts" & Baseline & 6 months & 12 months & 18 months & 24 months & 30 months & 36 months & 48 months & $\mathbf{p}$ \\
\hline SLEDAl-2K & 458 & $8.1 \pm 3.4$ & $4.9+3.3$ & $3.8 \pm 2.7$ & $3.8+3.2$ & $3.5 \pm 2.8$ & $2.6 \pm 2.8$ & $2.8 \pm 2.4$ & $2.7 \pm 2.1$ & $<0.000$ \\
\hline Prednisoned & 458 & $0.5 \pm 8.1$ & $6.7 \pm 4.6$ & $5.3 \pm 4.7$ & $5 \pm 4.8$ & $3.8 \pm 3.7$ & $3.5 \pm 2.9$ & $3.4 \pm 4.3$ & $3.4 \pm 4.5$ & $<0.0001$ \\
\hline DAS 28 & 309 & $3.4 \pm 1.7$ & $2.5 \pm 1.5$ & $2 \pm 1.4$ & $9 \pm 1.4$ & $1.7 \pm 1.3$ & $1.6 \pm 1.5$ & $1.5 \pm 1.4$ & $.4 \pm 1.4$ & $<0.0001$ \\
\hline CAst-a & 254 & $3.3 \pm 4.7$ & 43.3 & 2.2 .2 & $0.8 \pm 2.1$ & $0.6+1.8$ & $0.6 \pm 1.4$ & $0.6 \pm 1.4$ & $2+0.7$ & $<0.0001$ \\
\hline $\operatorname{CGA(0.3)}$ & 356 & $1.8 \pm 0.6$ & $1.2 \pm 0.7$ & $0.8 \pm 0.6$ & $0.8 \pm 0.7$ & $0.8 \pm 0.6$ & $0.7 \pm 0.6$ & $0.7 \pm 0.6$ & . $0.7 \pm 0.6$ & $<0.0001$ \\
\hline atigue VAS & 197 & $5.2 \pm 3.0$ & $4.3 \pm 2.8$ & $3.3 \pm 2.6$ & $2.8 \pm 2.7$ & $2.8 \pm 2.6$ & $2.5 \pm 2.9$ & $2.3 \pm 2.7$ & $2.4 \pm 2.9$ & $<0.0001$ \\
\hline Anti-dson & 131 & $230 \pm 354$ & $144 \pm 217$ & $118 \pm 179$ & \begin{tabular}{|l|}
$107 \pm 164$ \\
\end{tabular} & $99.2 \pm 162$ & $71.5 \pm 104$ & $74.4 \pm 145$ & $23.0 \pm 56.2$ & $c 0.006$ \\
\hline$=3(\mathrm{~m} / \mathrm{dll})$ & 458 & $50.1 \pm 38.8$ & $57.9 \pm 41.0$ & $61.2 \pm 41.8$ & $59.9 \pm 43.1$ & 62.1t41.8 & \begin{tabular}{|l}
$59.2 \pm 43.2$ \\
\end{tabular} & 64.9¥42.6 & $73.3 \pm 45.5$ & $<0.001$ \\
\hline$(\mathrm{mg} / \mathrm{d} \mathrm{d})$ & 458 & $7.7 \pm 7.7$ & $10.1+8.5$ & $11.2+9.3$ & 11.2t9.1 & $11.9 \pm 9.3$ & 11.049 .3 & $13.8 \pm 10.1$ & $13.6 \pm 9.7$ & $<0.006$ \\
\hline n prot & $n$ & 1.441 .1 & $0.8+0.9$ & $0.6+0.6$ & $0.6 \pm 0.7$ & $0.6 \pm 0.6$ & $0.7 \pm 0.8$ & $0.4 \pm 0.5$ & $0.6 \pm 0.6$ & 0.012 \\
\hline
\end{tabular}

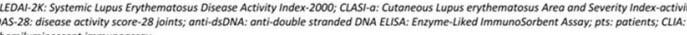

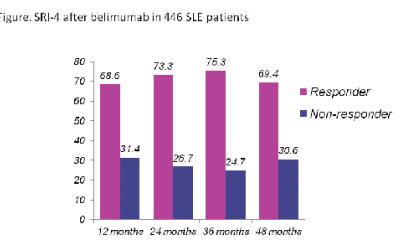

DOI: 10.1136/annrheumdis-2019-eular.3635

\section{FRI0200 REVIEW OF HYDROXYCHLOROQUINE USE AND DEVELOPMENT OF A REGIONAL STRATEGY TO} MINIMISE RETINAL TOXICITY

Ursula Laverty ${ }^{1}$, Gerard Reid ${ }^{2}$, Julie Silvestri ${ }^{2}$, Adrian Pendleton ${ }^{1} .{ }^{1}$ Musgrave Park Hospital, Belfast, United Kingdom; ${ }^{2}$ Royal Victoria Hospital, Belfast, United Kingdom

Background: Guidelines from the Royal College of Opthalmologists in February 2018 were developed for retinal screening for patients on hydroxychloroquine, as recent evidence suggests the risk of retinal toxicity is higher than previously reported. The prevalence of retinal toxicity in long term use appears to be $7.5 \%$ and depending on dose and duration of therapy can increase to $20-50 \%$ after 20 years of therapy. Risk is increased for patients taking more than $5 \mathrm{mg}$ per $\mathrm{kg}$ per day of hydroxychloroquine, patients on Tamoxifen and those with renal impairment. The guidelines recommend the use of a standardised referral proforma to help identify patients who are high risk.

Objectives: 1. Audit of Hydroxychloroquine use and retinal screening in the Belfast Health and Social Care Trust (BHSCT)

2. Develop a regional referral proforma and screening service for retinal toxicity

Methods: Patients who were treated with hydroxychloroquine, under the care of a consultant rheumatologist were identified on the database. A proforma was used to aid data collection and patients' electronic records were reviewed. We audited the use of hydroxychloroquine and retinal screening against current Royal College of Ophthalmology (RCO) guidelines. We designed a standardised referral proforma and regional screening strategy in conjunction with ophthalmology colleagues.

Results: There were 151 patients identified on hydroxychloroquine on the database. 40 of these patients had stopped hydroxychloroquine, 2 of which had retinal toxicity. Therefore the rate of retinal toxicity in this sample was $1.3 \%(2 / 151)$.

There were 111 patients who remained on hydroxychloroquine treatment with a female: male ratio of 9:1. Age range was from 22 to 84 , with a mean age of 55 . There were $44 \%$ of patients on hydroxychloroquine for rheumatoid arthritis, $25 \%$ had systemic lupus erythematosus, $8 \%$ had Sjogrens syndrome, $6 \%$ had pallindromic rheumatoid arthritis and $13 \%$ had other connective tissue diseases. The majority (79\%) of patients were on $200 \mathrm{mg}$ hydroxychloroquine daily and $19 \%$ were on $400 \mathrm{mg}$ daily. $6 \%$ of patients had an eGFR $<60$. No patients were on tamoxifen. $73 \%$ of patients were on hydroxychloroquine treatment for over 5 years. Retinal screening was overdue in $64 \%$ of patients.

Conclusion: In this sample, only $1.3 \%$ of patients had evidence of retinal toxicity, although $64 \%$ of patients were overdue retinal screening. We developed a referral proforma and a regional screening strategy in line with RCO guidelines. In order to meet the RCO guidelines, we recognise the need for substantial investment in regional ophthalmology services.
REFERENCES:

[1] Royal College of Ophthalmologists. (2018) Clinical Guidelines. Hydroxychloroquine and Chloroquine Retinopathy:Recommendations on Screening.

Disclosure of Interests: None declared

DOI: 10.1136/annrheumdis-2019-eular.5898

\section{FRI0201 REAL WORLD MEDICATION USE IN INCIDENT SYSTEMIC LUPUS ERYTHEMATOSUS AND LUPUS NEPHRITIS PATIENTS}

Lin Xie ${ }^{1}$, Furaha Kariburyo ${ }^{1}$, Janvi Sah ${ }^{1}$, Jennifer H. Lofland ${ }^{2}$, LI Nan ${ }^{3}$.

${ }^{1}$ STATinMED Research, Ann Arbor, United States of America; ${ }^{2}$ Janssen Global Commercial Strategic Organization, Horsham, United States of America; ${ }^{3} \mathrm{Janssen}$ Research and Development, LLC, Horsham, United States of America

Background: Systemic lupus erythematosus (SLE) is an autoimmune disease that causes inflammation in connective tissues and can involve multiple organs systems. Lupus nephritis (LN) is an inflammatory kidney disease caused by SLE. There is a gap in the literature regarding the standard of care in SLE and LN patients.

Objectives: This study generated real world medication use among SLE and $\mathrm{LN}$ patients.

Methods: This retrospective study used data from two large administrative databases in the US: Truven Health MarketScan ${ }^{\circledR}$ and Optum ${ }^{\circledR}$ databases to identify adult patients ( $\geq 18$ years of age) with $\geq 2$ medical claims on different dates for SLE or LN diagnoses from 01JAN2013-31DEC2015. SLE was identified using the International Classification of Diseases, 9th and 10th Revision, Clinical Modification [ICD-9-CM] codes (710.0) OR ICD-10-CM (M32.10-M32.19, 32.8, 32.9). LN was captured as a subset of SLE using [ICD-9-CM: 710.0 AND (581.81 or 582.81 or 583.81 ); OR (ICD-10-CM:M32.14)]. The first SLE or LN diagnosis was designated as the index date. Patients were required to have continuous health plan enrollment for 1 year pre-index date (baseline period) and 1 year postindex date (follow-up period) and no prior SLE/LN diagnosis claims or belimumab medical/prescription claim during the baseline period to ensure incident patients were captured. The Truven Health MarketScan ${ }^{\circledR}$ and Optum $^{\circledR}$ databases were pooled together and duplicates were identified and retained in MarketScan ${ }^{\circledR}$ only. Patient demographics and clinical characteristics during the baseline period were assessed. SLE treatment used during the follow-up period was evaluated and the proportion of patients that used SLE medications and average number of medical/prescription claims (\#Rx) for each medication were provided.

Results: A total of 31,345 patients were identified including 30,086 SLE and 1,259 LN patients. Key results are shown in Table 1. The mean age was 52.7 years for SLE and 48.3 years for LN patients. Over $80 \%$ of the patients were female, with a mean Charlson Comorbidity Index (CCl) score of 1.1 and 1.8 for SLE and LN patients respectively. The most common comorbidities at baseline were hypertension and infections. Corticosteroids ( $\mathrm{SLE}=58.3 \%$, \#Rx=4.5; $\mathrm{LN}=66.2 \%, \# \mathrm{Rx}=6.5$ ) and hydroxychloroquine ( $S L E=43.4 \%, \quad \# R x=5.8 ; \quad L N=40.7 \% \quad \# R x=6.2$ ) were the most commonly used SLE medications during 1-year follow up period. Approximately $2 \%$ of patients used biologics including belimumab (SLE $=1.1 \%$, $\# R x=8.8 ; \quad L N=1.4 \%, \quad \# R x=8.3) \quad$ and rituximab $\quad(S L E=0.9 \%, \quad \# R x=4.2 ;$ $\mathrm{LN}=2.1 \%, \# \mathrm{Rx}=4.0)$. 


\begin{tabular}{|c|c|c|}
\hline & $\begin{array}{c}\text { Systemic Lupus } \\
\text { Erythematosus } \\
(\mathrm{N}=\mathbf{3 0}, 086)\end{array}$ & $\begin{array}{l}\text { Lupus Nephritis } \\
\qquad(N=1,259)\end{array}$ \\
\hline \multicolumn{3}{|l|}{ SLE Medications, N (\%) } \\
\hline Corticosteroids $^{a}$ & $17533(58.3 \%)$ & $834(66.2 \%)$ \\
\hline Number of prescriptions, Mean (SD) & $4.5(5.0)$ & $6.5(6.0)$ \\
\hline Hydroxychloroquine & $13061(43.4 \%)$ & $513(40.7 \%)$ \\
\hline \multirow{2}{*}{ Number of prescriptions, Mean (SD) } & $5.8(3.6)$ & $6.2(3.7)$ \\
\hline & $11342(37.7 \%)$ & $271(21.5 \%)$ \\
\hline $\begin{array}{l}\text { Nonsteroidal Anti-Inflammatory Drugs (NSAIDs) } \\
\text { Number of prescriptions, Mean (SD) }\end{array}$ & $3.6(4.0)$ & $3.0(3.9)$ \\
\hline \multirow{2}{*}{$\begin{array}{l}\text { Angiotensin Converting Enzyme Inhibitor (ACE) } \\
\text { Number of prescriptions, Mean (SD) }\end{array}$} & $3827(12.7 \%)$ & $409(32.5 \%)$ \\
\hline & $5.4(3.7)$ & $5.4(3.7)$ \\
\hline \multirow{2}{*}{$\begin{array}{l}\text { Angiotensin II Receptor Blockers (ARB) } \\
\quad \text { Number of prescriptions, Mean (SD) }\end{array}$} & $3376(11.2 \%)$ & $318(25.3 \%)$ \\
\hline & $5.8(3.7)$ & $5.6(4.0)$ \\
\hline Methotrexate & $2884(9.6 \%)$ & $62(4.9 \%)$ \\
\hline Number of prescriptions, Mean (SD) & $5.5(4.1)$ & $4.9(3.3)$ \\
\hline $\begin{array}{l}\text { Number of prescriptions, Mean (SD) } \\
\text { Immunosuppressant }\end{array}$ & $1239(4.1 \%)$ & $83(6.6 \%)$ \\
\hline Number of prescriptions, Mean (SD) & $4.8(3.8)$ & $4.1(2.9)$ \\
\hline Cyclosporine Number of prescriptions, Mean (SD) & $1090(3.6 \%)$ & $40(3.2 \%)$ \\
\hline Number of prescriptions, Mean (SD) & $2.7(2.6)$ & $3.8(3.9)$ \\
\hline Mycophenolate Mofetil & $985(3.3 \%)$ & $397(31.5 \%)$ \\
\hline Number of prescriptions, Mean (SD) & $5.2(3.7)$ & $6.0(4.0)$ \\
\hline \multirow{2}{*}{$\begin{array}{ll}\text { Leflunomide } & \\
& \text { Number of prescriptions, Mean (SD) }\end{array}$} & $523(1.7 \%)$ & $15(1.2 \%)$ \\
\hline & $4.3(3.3)$ & $4.7(4.0)$ \\
\hline \multirow{2}{*}{$\begin{array}{l}\text { Belimumab } \\
\text { Number of medical/prescription claims, Mean (SD) }\end{array}$} & $306(1.0 \%)$ & $17(1.4 \%)$ \\
\hline & $8.8(6.5)$ & $8.3(6.7)$ \\
\hline \multirow{2}{*}{$\begin{array}{l}\text { Rituximab } \\
\text { Number of medical/prescription claims, Mean (SD) }\end{array}$} & $275(0.9 \%)$ & $26(2.1 \%)$ \\
\hline & $4.2(4.0)$ & $4.0(4.5)$ \\
\hline Cyclophosphamide & $98(0.3 \%)$ & $67(5.3 \%)$ \\
\hline Number of prescriptions, Mean (SD) & $5.0(5.0)$ & $4.4(2.7)$ \\
\hline \multicolumn{3}{|l|}{ SD: Standard Deviation } \\
\hline \multicolumn{3}{|c|}{ " ${ }^{2}$ orticosteroids: Prednisone, Betamethasone, Budesonide, Cortisone, Desoxycorticosterone, Dexamethasone } \\
\hline \multicolumn{3}{|c|}{$\begin{array}{l}\text { "2Corticosteroids: Prednisone, Betamethasone, Budesonide, Cortisone, Desoxycorticosterone, Dexamethasone } \\
\text { Fludrocortisone, Hydrocortisone, Methylprednisolone, Paramethasone, Prednisolone, Triamcinolone }\end{array}$} \\
\hline \multicolumn{3}{|c|}{ 'NSAIDs: Diclofenac, Bromfenac, Choline and Magnesium salicylate, Methanamine and sodium salicylate, } \\
\hline \multicolumn{3}{|c|}{ Fenoprofen, Flurbiprofen, Ketoprofen, Naproxen, Oxaprozin, Sulindac, Piroxicam, Etodolac, Meloxicam, } \\
\hline \multirow{2}{*}{\multicolumn{3}{|c|}{$\begin{array}{l}\text { Nabumetone, Celecoxib/Celebrex, Indomethacin, Mefenamic acid, Meclofenamate, Diflunisal, Tolmetin, } \\
\text { Salsalate, Aspirin, Ibuprofen, Ketorolac }\end{array}$}} \\
\hline & & \\
\hline \multirow{2}{*}{\multicolumn{3}{|c|}{$\begin{array}{l}\text { 'ACE: Captopril, Enalapril/ Enalał } \\
\text { Trandolapril, Benazepril }\end{array}$}} \\
\hline & & \\
\hline \multicolumn{3}{|c|}{ 'ARB: Candesartan, Eprosartan, Irbesartan, Losartan, Olmesartan, Telmisartan, Valsartan, Azilsartan } \\
\hline
\end{tabular}

Conclusion: Our findings indicate a nominal use of biologics ( $2 \%$ ) among SLE and LN patients. Corticosteroids and hydroxychloroquine were the most commonly used SLE treatments. These data reveal an unmet need for availability of advanced therapy to treat SLE and LN. Future studies are warranted to understand the underlying causes.

Disclosure of Interests: Lin Xie Grant/research support from: Janssen Research \& Development, LLC, Furaha Kariburyo Grant/research support from: Janssen Research \& Development, LLC, Janvi Sah Grant/research support from: Janssen Research \& Development, LLC, Jennifer H. Lofland Employee of: Janssen Global Commercial Strategic Organization, Nan Li Shareholder of: J\&J, Employee of: Janssen Scientific Affairs, LLC DOI: 10.1136/annrheumdis-2019-eular.543

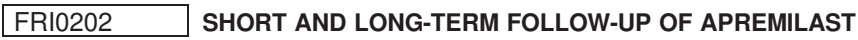 THERAPY IN REFRACTORY SKIN LUPUS LESIONS}

José Luis Martín-Varillas ${ }^{1}$, Belén Atienza-Mateo ${ }^{1}$, J. Loricera ${ }^{1}$, Susana Armesto ${ }^{1}$, Eduardo Cuende ${ }^{2}$, Juanjo J. Alegre-Sancho ${ }^{3}$, Clara Moriano ${ }^{4}$, Vanesa Calvo-Río ${ }^{1}$, Monica Calderón-Goercke ${ }^{1}$, D. Prieto-Peña ${ }^{1}$, Lara Sánchez Bilbao ${ }^{1}$, Iñigo González-Mazón ${ }^{1}$, C. González-Vela ${ }^{1}$, J. Luis Hernández ${ }^{1}$,

Santos Castañeda ${ }^{5}$, Miguel A. González-Gay ${ }^{1}$, Ricardo Blanco ${ }^{1} .{ }^{1}$ H.U.M

Valdecilla, Santander, Spain; ${ }^{2}$ H. U. Príncipe de Asturias, Madrid, Spain; ${ }^{3}$ H. Dr. Peset, Valencia, Spain; ${ }^{4}$ H. de León, León, Spain; ${ }^{5}$ H. La Princesa, Madrid, Spain

Background: Treatment of skin lupus lesions (SLL) was based on topical therapy (corticosteroids, calcineurin inhibitors), systemic corticosteroids, antimalarials and immunomodulatory drugs including thalidomide. However, there are refractory patients to conventional treatment. Apremilast, an inhibitor of phosphodiesterase-4 (PDE-4), may be useful in these cases. Objectives: Our objective was to assess the efficacy and safety of apremilast.

Methods: We set up an observational study of 8 patients with diagnosis of refractory SLL and treatment with apremilast at a standard dose of 30 $\mathrm{mg} / 12$ hours. The outcome was the presence of improvement and the appearance of side effects.

Results: 8 patients $(7$ female/ 1 male) with mean age of $39.9 \pm 10.6$ years with SLL were studied. Patients were diagnosed as follows: discoid lupus $(n=5)$ and systemic lupus erythematosus (SLE) $(n=3)$. Patients with SLE were classified as lupus panniculitis $(n=1)$, polycyclic ring lupus $(n=1)$ and psoriasiform lupus $(n=1)$. All skin lesions were confirmed by biopsy (table).

Before apremilast, all patients had received conventional therapy without improvement: topical corticosteroids $(n=8)$, topical tacrolimus $(n=4)$, oral corticosteroids $(n=5)$, antimalarials $(n=8)$, thalidomide $(n=1)$, belimumab $(n=3)$ and rituximab $(n=2)$.

The time between SLL diagnosis and apremilast beginning was 145.1 \pm 79.4 months. After a mean follow-up of $14.4 \pm 4.8$ months, all patients presented improvement of skin lesions (4 of them with complete response). Due to the appearance of gastrointestinal symptoms (diarrhoea, vomiting) it was necessary to reduce the dose of apremilast to $30 \mathrm{mg} /$ day in one patient and finally, it was discontinued due to no improvement with antiemetic and probiotic treatment.

Conclusion: Apremilast seems useful and relatively safe in patients with refractory SLL to conventional treatment.

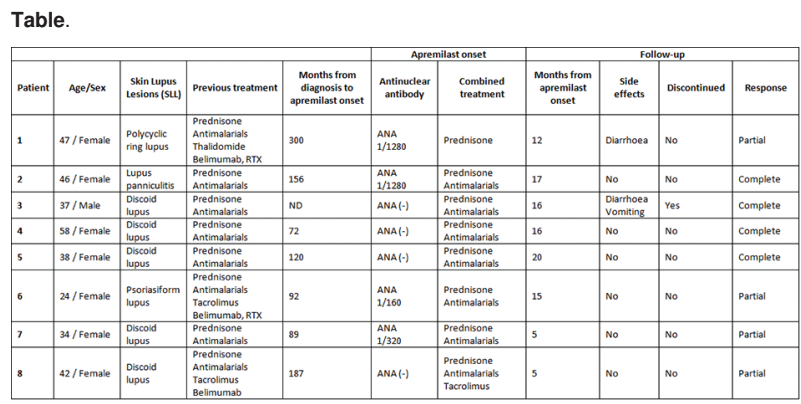

Disclosure of Interests: José Luis Martín-Varillas: None declared, Belén Atienza-Mateo: None declared, J. Loricera: None declared, Susana Armesto: None declared, Eduardo Cuende: None declared, Juanjo J Alegre-Sancho: None declared, Clara Moriano: None declared, Vanesa Calvo-Río: None declared, Monica Calderón-Goercke: None declared, D. Prieto-Peña: None declared, Lara Sánchez Bilbao: None declared, Iñigo González-Mazón: None declared, C. González-Vela: None declared, J. Luis Hernández: None declared, Santos Castañeda Consultant for: Amgen, BMS, Pfizer, Lilly, MSD, Roche, Sanofi, UCB, Miguel A González-Gay Grant/research support from: Prof. MA Gonzalez-Gay received grants/research supports from Abbvie, MSD, Jansen and Roche., Speakers bureau: Consultation fees/participation in company sponsored speaker s bureau from Pfizer, Lilly, Sobi, Celgene, Novartis, Roche and Sanofi., Ricardo Blanco Grant/research support from: Abbvie, MSD, and Roche, Consultant for: Abbvie, Pfizer, Roche, Bristol-Myers, Janssen, Speakers bureau: Abbvie, Pfizer, Roche, Bristol-Myers, Janssen DOI: 10.1136/annrheumdis-2019-eular.6978

\section{FRI0203 CONCORDANCE OF DORIS REMISSION CRITERIA WITH THE TREATING PHYSICIAN'S (DORIS-)INDEPENDENT REMISSION JUDGMENT IN A SLE-COHORT AT A TERTIARY CENTER}

Johanna Mucke, Christina Duesing, Gamal Chehab, Matthias Schneider. Policlinic for Rheumatology and Hiller Research Centre for Rheumatology, Heinrich-HeineUniversity Duesseldort, Duesseldorf, Germany

Background: The definition of an accurate target for a treat to target (T2T) approach in SLE has been challenging over the past years. Recently four definitions of remission were presented by the international DORIS task force. ${ }^{1}$

Objectives: Aim of this study was to evaluate the frequency of remission in our outpatient SLE cohort and to assess feasibility and concordance of the remission definitions with the treating physician's opinion regarding the patient's state.

Methods: In this monocentric cross-sectional study patients with SLE according to the 1997 American College of Rheumatology (ACR) criteria were enrolled and assessed between September 2016 and December 2017. DORIS remission definitions were applied and demographic and laboratory data as well as disease activity (SLEDAI), steroid dosage and physician global assessment were evaluated. After the clinical consultation, the treating physicians answered the question if his/her patient was in remission. 